\title{
Evaluation of a Social Web-based Telehealth System
}

\author{
Jaspaljeet Singh Dhillon, Burkhard C. Wünsche, Christof Lutteroth \\ Department of Computer Science \\ University of Auckland \\ Private Bag 92019, Auckland, New Zealand \\ jran055@aucklanduni.ac.nz, \{burkhard, lutteroth\}@cs.auckland.ac.nz
}

\begin{abstract}
Increasing healthcare costs and demographic changes necessitate healthcare interventions that foster independent care. Existing telehealth systems are focused on treating diseases instead of preventing them, suffer from high initial costs, lack extensibility, and do not address the social and psychological needs of patients. We developed Healthcare4Life, an online telehealth system for seniors. In this paper, we report the results of a 6-week user study involving 43 seniors (aged 60 and above). Results indicate that seniors are ready to take charge of their health via a web-based telehealth system, provided there are suitable health applications for them to use. The social networking features require a sufficiently large user base to be useful. The results also suggest that web-based telehealth solutions can positively change the attitude of seniors towards managing their own healthcare.
\end{abstract}

\section{Author Keywords}

Telehealth, seniors, evaluation, Web 2.0

\section{ACM Classification Keywords}

H5.m. Information interfaces and presentation (e.g., HCI): Miscellaneous

\section{INTRODUCTION}

Home telehealth systems enable health professionals to efficiently collect vital signs data from patients with chronic diseases residing at their homes. These applications are mostly focused on managing diseases rather than preventing them and are typically standalone systems with limited functionality. Based on an analysis of existing consumer health informatics systems we developed Healthcare4Life (HC4L), a novel telehealth system which is ubiquitous, extendable by third parties, contains social aspects, and puts the user in control.

In this paper, we present a summative evaluation of HC4L. The goal of this study was to test the feasibility and acceptability of a web-based health management system in seniors. The secondary objective was to assess the user satisfaction, effectiveness of the system, its content and user interface.

The rest of the paper is organized as follows: we give a brief overview of HC4L, explain the methodology used in

Permission to make digital or hard copies of all or part of this work for personal or classroom use is granted without fee provided that copies are not made or distributed for profit or commercial advantage and that copies bear this notice and the full citation on the first page. To copy otherwise, or republish, to post on servers or to redistribute to lists, requires prior specific permission and/or a fee.

OZCHI'12, November 26-30, 2012, Melbourne, Victoria, Australia.

Copyright 2012 ACM 978-1-4503-1438-1/12/11 ..\$10.00. the study for evaluating the system, present and discuss the results, and finally offer some conclusions.

\section{OVERVIEW OF HEALTHCARE4LIFE}

$\mathrm{HC} 4 \mathrm{~L}$ is an extendable ubiquitous patient-centric system that combines the power of social networking with telehealth functionalities for enabling patients, especially seniors, to manage their health independently from home. HC4L has gone through a user-centered design process that is beyond the scope of this paper, but described elsewhere (Singh et al., 2010; Dhillon et al., 2011; Dhillon et al., 2012a). The system was developed using Google's OpenSocial technology and Drupal CMS (Dhillon et al., 2012b). HC4L encourages positive lifestyle changes by letting seniors manage their own healthcare goals. Patients are able to locate other patients suffering from similar diseases - enabling them to share experiences, motivate each other, and engage in healthrelated activities (e.g. exercises) via applications available in the system. Similar to Facebook, the system has an open architecture that enables third-party providers to add new content and functionalities. Developers can design and deploy applications by using the OpenSocial standard, e.g. in the form of serious games, interactive web pages and expert systems.

Currently, we have developed and hosted several health monitoring applications, including a weight, vital signs and exercise tracker that records the data entered by the patients and gives visual feedback in the form of graphs and bar charts. We have also developed a social memory game that allows users to test their memory by finding matching pairs of cards. In order to provide motivation and feedback, all applications contribute to a general weekly score, which is presented to the user as an overall performance percentage.

\section{METHODOLOGY}

\section{Procedure}

The study followed a mixed method approach. The telehealth system was made accessible via the web using the domain Healthcare4Life.com. A 6-week live user evaluation of the HC4L system was carried out from June to August 2012.

Participants were recruited by posting advertisements in senior community centres, clubs and retirement homes in New Zealand. Participants were expected to be aged $60+$. Prior knowledge or experience with computers was not needed.

The evaluation was preceded by a one-hour session comprising of a system demo and basic training to use the system at three senior community centres on different 
dates. The objectives were to provide an overview about HC4L and the user study, to discuss participant commitment, and to provide a hands-on experience with the system. In order to maintain participant confidentiality and anonymity, users were advised to avoid using their real name or part of their real name as their username in the system. A printed user guide containing step-by-step instructions to use the basic features of HC4L was provided. Details of the user study and a softcopy of the user guide were made accessible via the HC4L homepage.

Participants were encouraged to use the system at their own pace over a 6 week period. Activities in the system were logged for analysis purposes. Reminders to use HC4L were provided via email once every week. Participants had to complete 3 instances of questionnaires at different junctures online: after the initial meeting, at the end of the $3^{\text {rd }}$ week and at the end of the $6^{\text {th }}$ week (see Table 1 ).

\begin{tabular}{|c|l|l|c|}
\hline $\begin{array}{c}\text { Survey } \\
\text { No. }\end{array}$ & $\begin{array}{c}\text { Assessment } \\
\text { Period }\end{array}$ & $\begin{array}{c}\text { Content of } \\
\text { Questionnaire }\end{array}$ & $\begin{array}{c}\text { Completed } \\
\text { (n) }\end{array}$ \\
\hline 1 & Initial Meeting & $\begin{array}{l}\text { Demographics, } \\
\text { MHLC }\end{array}$ & 43 \\
\hline 2 & End of Week 3 & MHLC, IMI, SUS & 24 \\
\hline 3 & End of Week 6 & $\begin{array}{l}\text { Additional Likert } \\
\text { scale and open-ended } \\
\text { items }\end{array}$ & 21 \\
\hline
\end{tabular}

Table 1. Content of Questionnaires.

\section{Instruments}

The questionnaires incorporated existing established questionnaire scales as explained below: MHLC, IMI and SUS. In order to keep the questionnaire simple for the seniors, the shortened form of these scales was used. Other items contained in the questionnaire recorded information on participants' demographics and specific aspects about HC4L.

The Multidimensional Health Locus of Control (MHLC) is a scale developed to assess users' perception whether health is controlled by internal or external factors (Wallston et al., 1978). The scale was employed to investigate whether HC4L can positively affect users' atttitude towards managing their health, i.e. to make them realise that health is not just controlled by external forces. The scale comprises 3 subscales: internal, powerful others and chance. It has 18 items (6 items for each subscale). Following previous studies (Bennett et al., 1995; Baghaei et al., 2011), the shortened version of the scale was used, where 9 items (3 items for each subscale) were chosen from the original MHLC with 6 response choices, ranging from strongly disagree (1) to strongly agree (6). In order to detect differences in participants' attitude, they had to complete the MHLC scale twice: before the evaluation and at the end of the $3^{\text {rd }}$ week of the study. It was anticipated that the short duration of the study would not be sufficient to gauge behavioral change of seniors towards their health management. Therefore, we examined the results as a signal of possible future behavioral change (Torning \& Oinas- Kukkonen, 2009).
The Intrinsic Motivation Inventory (IMI) is a measurement tool developed to determine an individual's levels of intrinsic motivation for a target activity (Ryan, 1982). The scale was adapted to evaluate participants' subjective experience in their interaction with $\mathrm{HC} 4 \mathrm{~L}$, including interest/enjoyment, perceived competence, effort, value/usefulness, and felt pressure/tension. Several versions of the scale are available for use. We used a shortened version by taking 15 items (3 items for each subscale), which were randomly distributed in the questionnaire. Items of the IMI scales as cited by McAuley et al. (1989) can be modified slightly to fit specific activities without effecting its reliability or validity. Therefore, an item such as "I would describe this activity as very interesting" was changed to "I would describe the system as very interesting".

User satisfaction with the system was measured using the System Usability Scale (SUS). This is a simple scale comprising 10 items rated on a 5-point Likert scale from strongly disagree (1) to strongly agree (5) that provides a global view of usability (Brooke, 1996). Participants' responses to the statements are calculated as a single score, ranging from 0 to 100 , with a higher score indicating a better usability (Bangor et al., 2009). Although SUS was originally designed to provide a general usability score (unidimensional) of a product, recent research by Lewis and Sauro (2009) showed that it can also provide three more specific measures: overall system satisfaction, usability and learnability.

\section{RESULTS AND DISCUSSION}

\section{Socio-demographic Characteristics}

The initial sample consisted of 43 seniors aged 60 to 85 (mean age $70, \mathrm{SD}=17.68$ ). Most of the participants were female $(62.79 \%)$ and European $(81.40 \%)$. Only $37.21 \%$ were living alone, with the rest living with either their spouse/partner or children. The majority of the participants were active computer users $(88.37 \%)$ using a computer almost every day. Less than half of them $(44.19 \%)$ used social networking websites such as Facebook. Only $32.56 \%$ used self-care tools (e.g. blood pressure cuffs, glucometers or health websites). Most of the participants $(65.12 \%)$ had heard about telehealth.

\section{System Usage Data}

HC4L was accessed 181 times, by 43 participants. The average number of logins per person over 6 weeks was 4.21 with SD 4.96 and median 2. It was a challenge to obtain commitment from seniors to engage in the user study over 6 weeks. Although the study began with a larger sample, the user retention rate dropped over time (see Figure 1). This is in fact a common issue in a live user study (Baghaei et al., 2011). However, a few participants continued to use the system after the $6^{\text {th }}$ week. Fifteen participants $(34.88 \%)$ logged in only once. It is interesting to note that the participant with the highest frequency of usage (25 logins) had very little experience with computers, but was very keen to learn how to use the system well. 


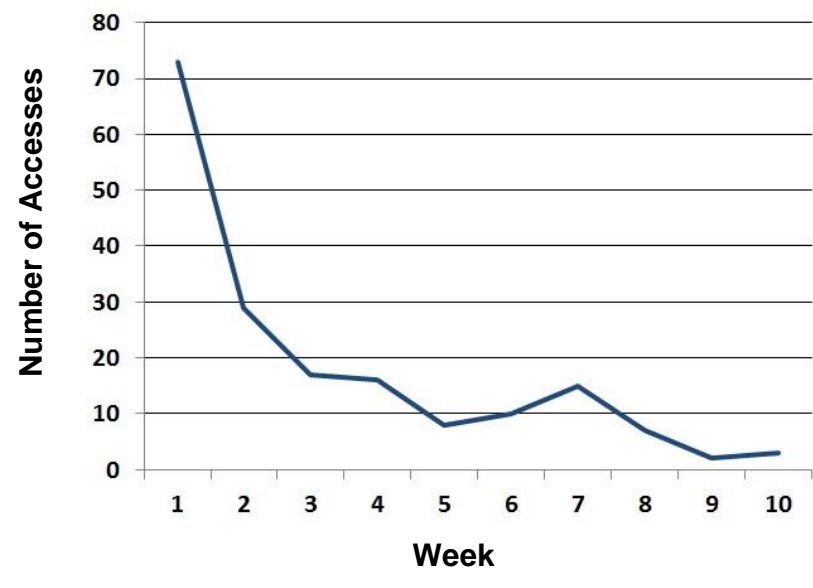

Figure 1. Participant Retention Rate.

Figure 2 depicts the overall usage of the 6 main functionalities provided in the system. It is apparent that the Health Apps feature was the most popular (35\%) among the participants. The Facebook-like comment page termed Activities was the second most commonly used feature $(22 \%)$. This was followed by the Friends page $(17 \%)$. The Settings page was the least used functionality (4\%) among the participants. Along with the overall usage of the main functionalities, Figure 2 shows popularity of specific health applications available in the system. The Vital Tracker was the most frequently (29\%) used application. Exercise Tracker was the second most popular one (28\%), followed by the Weight Tracker $(22 \%)$. The Calorie Calculator was least used by the participants $(8 \%)$.

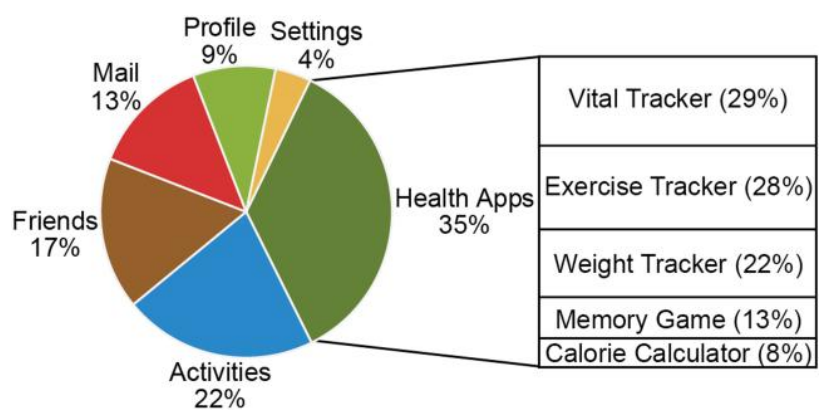

Figure 2. Participants' Activities in HC4L.

\section{User Satisfaction and Acceptability}

Participants rated the usability of the system positively. Twenty-four of them completed the SUS scale with scores ranging between 35 and 100, with a median of 65 . The average SUS score is 68.33 , with only two participants rating it below 50\% (not acceptable). The adjective rating of the mean SUS score is 'OK', which indicates it is an acceptable system (Bangor et al., 2009). The mean SUS score obtained can be considered average as Sauro (2011) claims the average SUS score of 500 evaluation studies that have administered SUS is 68 .

Open-ended questions added in the questionnaire were useful for gaining insight into participants' perception of HC4L. The most frequent positive and negative comments are provided in Table 2. Overall, the system was found to be straightforward to use and well accepted by the participants. The participants were keen about the idea of being able to access a wide variety of health applications via a single interface. They favored the health tracking applications provided in the system. However, it became apparent that the applications need to be carefully designed to be useful. For example, the Calorie Calculator, a free iGoogle gadget added from LabPixies.com, was least liked by the participants (see Figure 2). Issues reported include the "extreme tediousness" of the application, "foods are mostly American", and "it is not clear where to enter the data". Other applications in the system were regarded as interesting even though there were some minor issues. For instance, the Multiplayer Memory Game was considered as more enjoyable than the commonly found single player memory games, but the participants were not able to play it often because nobody was online. It was significant that most of the participants were not interested to use the social features provided in the system. Four active participants of the study expressed disappointment that their friend requests were not responded to. Another criticism was the lack of available applications.

\begin{tabular}{|l|c|}
\hline \multicolumn{1}{|c|}{ Positive Responses } & Frequency (\%) \\
\hline I like the idea of it. & $26 \%$ \\
\hline It is easy to use. & $23 \%$ \\
\hline $\begin{array}{l}\text { The health applications are a great help to keep } \\
\text { track of ones health. }\end{array}$ & $16 \%$ \\
\hline \multicolumn{1}{|c|}{ Negative Responses } & Frequency (\%) \\
\hline $\begin{array}{l}\text { Sorting out calories values for foods seems a lot } \\
\text { of trouble (Calorie Calculator). }\end{array}$ & $21 \%$ \\
\hline $\begin{array}{l}\text { I am not so keen on the social Facebook-like } \\
\text { aspects of the system. }\end{array}$ & $18 \%$ \\
\hline Limited applications. & $15 \%$ \\
\hline
\end{tabular}

Table 2. Most Common Positive and Negative Comments about HC4L.

\section{Change in Attitude}

Table 3 reports the mean change scores for those participants who completed both the pre- and post-task questionnaires. Change scores for each MHLC subscale were calculated by subtracting baseline scores from follow-up scores. Summed scores for each subscale range from 3 to 18 with higher scores indicating higher agreement that internal factors or external factors (chance, powerful others) determine health.

\begin{tabular}{|l|c|c|c|}
\hline Subscale & M & SD & Range \\
\hline Internal & .04 & 1.04 & -4 to 2 \\
\hline Powerful others & -.29 & 1.27 & -10 to 6 \\
\hline Chance & -.10 & 1.23 & -6 to 5 \\
\hline
\end{tabular}

Table 3. Change in MHLC Subscales $(n=23)$.

The findings show that there were some improvements on all of the 3 subscales. Participants responses for powerful others, which denotes health is controlled by others such as doctors, reduced significantly by -.29 . This suggests that the use of HC4L can reduce participants' reliance on others, such as health professionals.

\section{Motivation}

Table 4 presents the mean values and standard deviations of the five pre-selected subscales of the IMI (subscale range: $1-7$ ). It also illustrates the scores of 2 different age groups of seniors. 


\begin{tabular}{|l|c|c|c|}
\hline Subscale & $\begin{array}{c}\text { All } \\
(\mathbf{n = ~ 2 4})\end{array}$ & $\begin{array}{c}\text { Age 60-69 } \\
(\mathbf{n = 1 2})\end{array}$ & $\begin{array}{c}\text { Age 70-85 } \\
(\mathbf{n = ~ 1 2})\end{array}$ \\
\hline Interest/Enjoyment & $4.40 \pm 1.68$ & $4.42 \pm 1.73$ & $4.39 \pm 1.70$ \\
\hline $\begin{array}{l}\text { Perceived } \\
\text { Competence }\end{array}$ & $4.39 \pm 1.78$ & $4.89 \pm 1.52$ & $3.89 \pm 1.94$ \\
\hline Effort/Importance & $4.11 \pm 1.58$ & $4.11 \pm 1.57$ & $4.11 \pm 1.56$ \\
\hline Pressure/Tension & $2.61 \pm 1.56$ & $2.67 \pm 1.45$ & $2.56 \pm 1.69$ \\
\hline Value/Usefulness & $4.25 \pm 1.81$ & $4.53 \pm 1.83$ & $3.97 \pm 1.75$ \\
\hline
\end{tabular}

Table 4. Subscale Findings of the IMI $(M \pm S D)$.

Excluding the pressure/tension scale, the results show mid scores in the range $4.11-4.40$. Results imply that the participants were fairly interested in the system, they were adequately competent, involved reasonable effort in using the system and felt that the system has some value or utility for them. The pressure/tension subscale obtained a low score indicating that the participants did not experience stress while using the system. There are significant differences between the scores obtained for perceived competence and value/usefullness by the two age categories of seniors. It is apparent that seniors of age range 60-69 are more competent and find the system more valuable than the older seniors. On the whole, participants have rated their subjective experience with HC4L as satisfactory.

\section{LIMITATIONS}

Most participants had experience with computers and results for users unfamiliar with computers may vary. The small size of the sample did not allow us to determine whether the system is more useful for some subgroups (e.g. particular health issues, psychological or emotional conditions).

\section{CONCLUSION}

The idea of using the web to manage health is well accepted by seniors, but there should be a range of health applications which are tailored towards their individual needs (health conditions). The social networking functionalities require a sufficiently large user base and would appeal more if they provided more functional communication among users. The results further suggest that web-based telehealth systems have the potential to positively change the attitude of users towards their health management, i.e. users realise that their health is not controlled by health professionals, but that they have the power to affect their well-being positively.

\section{ACKNOWLEDGMENTS}

We would like to thank the participants for their kind support, patience and valuable feedback. We appreciate WellingtonICT, SeniorNet Eden-Roskill and SeniorNet HBC for advertising the study and for allowing us to use their premise to conduct the training. We also thank Nilufar Baghaei for her inputs in conducting the study.

\section{REFERENCES}

Baghaei, N., Kimani, S., Freyne, J., Brindal, E., Berkovsky, S. and Smith, G. Engaging families in lifestyle changes through social networking. Int. Journal of Human-Computer Interaction, 27, 10 (2011), 971-990.

Bangor, A., Kortum, P., Miller, J. and Bailey, B. Determining what individual sus scores mean: adding an adjective rating scale. Journal of Usability Studies, 4, 3(2009), 114-123.

Brooke, J. SUS: A quick and dirty usability Scale. In: P.W. Jordan, B. Thomas, B.A. Weerdmeester \& I.L. McClelland (Eds.), Usability Evaluation in Industry. (1996) London: Taylor \& Francis.

Yu, C.H., Bahniwal, R., Laupacis, A., Leung, E., Orr, M.S. and Straus, S.E. Systematic review and evaluation of web-accessible tools for management of diabetes and related cardiovascular risk factors by patients and healthcare providers. Journal of the American Medical Informatics Association (2012).

Dhillon, J.S., Ramos, C., Wünsche, B.C. and Lutteroth, C. 2011. Designing a web-based telehealth system for elderly people: An interview study in New Zealand. In Proc. CBMS 2011, (2011), 1-6.

Dhillon, J.S., Wünsche, B.C. and Lutteroth, C. Evaluation of a web-based telehealth system: A preliminary investigation with seniors in New Zealand. In Proc. CHINZ 2012. ACM Press (2012a).

Dhillon, J.S., Ramos, C., Wünsche, B.C. and Lutteroth, C. Evaluation of web 2.0 technologies for developing online telehealth systems. In Proc. HIKM 2012, 129, (2012b), 21-30.

Lewis, J.R. and Sauro, J. The factor structure of the system usability scale. In Proc. HCD 2009, 94-103.

McAuley E., Duncan T. and Tammen V.V. Psychometric properties of the Intrinsic Motivation Inventory in a competitive sport setting: a confirmatory factor analysis. Research Quarterly for Exercise \& Sport, 60, 1, (1989), 48-58.

Singh J., Wünsche, B.C. and Lutteroth, C. Framework for Healthcare4Life: a ubiquitous patient-centric telehealth system. In Proc. CHINZ 2010. ACM Press (2010).

Ryan, R.M. Control and information in the intrapersonal sphere: An extension of cognitive evaluation theory. Journal of Personality and Social Psychology, 43, 3 (1982), 450-461.

Sauro, J. Measuring Usability with the System Usability Scale (SUS), (2011). Retrieved from http://www.measuringusability.com/sus.php

Torning, K. and Oinas-Kukkonen, H. Persuasive system design: State of the art and future directions, In Proc. of Persuasive 2009.

Wallston, K.A., Wallston, B.S. and DeVellis, R. Development of the Multidimensional Health Locus of Control (MHLC) Scales. Health Educ Behav, 6, 1 (1978), 160-170. 